\title{
A NOTE ON CONVEX AND BAZILEVIČ FUNCTIONS
}

\section{NUNOKAWA}

1. Let $f(z)=z+\sum_{n=2}^{\infty} a_{n} z^{n}$ be regular, univalent in $|z|<1$ and map $|z|<1$ onto a domain which is starlike with respect to the origin. Then we call $f(z)$ a starlike function. It is well known that a function $f(z)$ is starlike in $|z|<1$ if and only if

$$
\operatorname{Re} \frac{z f^{\prime}(z)}{f(z)}>0 \quad \text { in }|z|<1 .
$$

Let $f(z)=z+\sum_{n=2}^{\infty} a_{n} z^{n}$ be regular, univalent in $|z|<1$ and map $|z|<1$ onto a convex domain. Then we call $f(z)$ a convex function.

It is well known that a regular function $f(z)$ is convex if and only if

$$
1+\operatorname{Re} \frac{z f^{\prime \prime}(z)}{f^{\prime}(z)}>0 \quad \text { in }|z|<1 .
$$

Every convex function is a starlike function [4].

Let $L(r)$ denote the length of the closed curve $C(r)$ which is the image of the circle $|z|=r<1$ under the mapping $w=f(z)$ and $A(r)$ the area enclosed by $C(r)$.

Recently Thomas [6], [8] has shown that if $f(z)$ is a starlike function, then

$$
L(r) \leqq 2(\pi A(r))^{1 / 2}\left(1+\log \frac{1+r}{1-r}\right) .
$$

In this note, for the convex functions we obtain a stronger result than (1).

TheOREM 1. Let $f(z)=z+\sum_{n=2}^{\infty} a_{n} z^{n}$ be a convex function. Then we have

$$
L(r)=0\left(A(r) \log \frac{1}{1-r}\right)^{1 / 2} \quad \text { as } r \rightarrow 1 .
$$

Proof. Since $f(z)$ is a univalent function we can get

Received by the editors May 26, 1969. 


$$
\begin{aligned}
L(r)= & \int_{0}^{2 \pi}\left|z f^{\prime}(z)\right| d \theta \leqq \int_{0}^{2 \pi} \int_{0}^{r}\left|z f^{\prime \prime}(z)+f^{\prime}(z)\right| d \rho d \theta \\
= & \int_{0}^{r} \int_{0}^{2 \pi}\left|f^{\prime}(z)\left(1+\frac{z f^{\prime \prime}(z)}{f^{\prime}(z)}\right)\right| d \theta d \rho \\
= & \int_{0}^{r_{1}} \int_{0}^{2 \pi}\left|f^{\prime}(z)\left(1+\frac{2 f^{\prime \prime}(z)}{f^{\prime}(z)}\right)\right| d \theta d \rho \\
& +\int_{r_{1}}^{r} \int_{0}^{2 \pi}\left|f^{\prime}(z)\left(1+\frac{2 f^{\prime \prime}(z)}{f^{\prime}(z)}\right)\right| d \theta d \rho
\end{aligned}
$$

where $r_{1}$ is a fixed constant and $0<r_{1}<r<1$.

Therefore we have

$$
\begin{aligned}
& \leqq C+\left(\int_{r_{1}}^{r} \int_{0}^{2 \pi} \rho\left|f^{\prime}(z)\right|^{2} d \theta d \rho\right)^{1 / 2}\left(\int_{r_{1}}^{r} \int_{0}^{2 \pi} \frac{1}{\rho}\left|1+\frac{z f^{\prime \prime}(z)}{f^{\prime}(z)}\right|^{2} d \theta d \rho\right)^{1 / 2} \\
& \leqq C+\left(\int_{0}^{r} \int_{0}^{2 \pi} \rho\left|f^{\prime}(z)\right|^{2} d \theta d \rho\right)^{1 / 2}\left(\frac{1}{r_{1}} \int_{0}^{r} \int_{0}^{2 \pi}\left|1+\frac{z f^{\prime \prime}(z)}{f^{\prime}(z)}\right|^{2} d \theta d \rho\right)^{1 / 2} \\
& \leqq C+\left(\frac{A(r)}{r_{1}}\right)^{1 / 2}\left(\int_{0}^{r} \int_{0}^{2 \pi}\left|1+\frac{z f^{\prime \prime}(z)}{f^{\prime}(z)}\right|^{2} d \theta d \rho\right)^{1 / 2}
\end{aligned}
$$

where $C$ is a bounded constant.

On the other hand, it is well known that (see for instance [3, p. 294])

$$
\int_{0}^{r} \int_{0}^{2 \pi}\left|1+\frac{z f^{\prime \prime}(z)}{f^{\prime}(z)}\right|^{2} d \theta d \rho \leqq 4 \pi \log \frac{1+r}{1-r} .
$$

This completes our proof and a question arises whether there is a positive constant $\alpha$ and a convex function $f(z)$ for which

$$
L(r) \geqq \alpha\left(A(r) \log \frac{1}{1-r}\right)^{1 / 2} \quad \text { as } r \rightarrow 1 .
$$

I can not give an answer for this question.

2. A function $f(z)=z+\sum_{n=2}^{\infty} a_{n} z^{n}$ that is regular in $|z|<1$ is called a Bazilevic function of type $\beta$, if there exists a starlike function $g(z)$ and $\beta>0$ such that

$$
\operatorname{Re} \frac{z f^{\prime}(z)}{f(z)^{1-\beta} g(z)^{\beta}}>0 \quad \text { in }|z|<1 .
$$


Bazilevič [1] has shown that each such function is univalent in $|z|<1$. Every starlike function is a Bazilevič function of type $\beta$.

Then the following theorems have been obtained in [6], [7] and [2], [5].

TheOREM A. Let $f(z)$ be a Bazilevič function of type $\beta, 0<\beta \leqq 1$ and let

$$
M(r)=\max _{|z|=r}\left|f\left(r e^{i \theta}\right)\right| \leqq(1-r)^{-\alpha} \quad 0<\alpha \leqq 2 .
$$

Then

$$
L(r)=O(1-r)^{-\alpha} \quad \text { as } r \rightarrow 1 .
$$

Theorem B. Let $f(z)$ be a Bazilevic function of type $\beta, \arg f(z)$ be a function of bounded variation on $|z|=r<1$ and let

$$
M(r)=\max _{|z|=r}\left|f\left(r e^{i \theta}\right)\right| \leqq(1-r)^{-\alpha} \quad 0<\alpha \leqq 2 .
$$

Then we have

$$
L(r)=O(1-r)^{-\alpha} \quad \text { as } r \rightarrow 1 .
$$

Theorem 2. The results of Theorem $\mathrm{A}$ and Theorem $\mathrm{B}$ are sharp for each $\alpha, 0<\alpha \leqq 2$ and therefore $O$ in (2) and (3) can not be replaced by $o$.

Proof. It is easily verified that the function

$$
f(z)=\frac{z}{(1-z)^{\alpha}}, \quad 0<\alpha \leqq 2
$$

is a starlike function $[2$, p. 216] and

$$
M(r) \leqq(1-r)^{-\alpha} .
$$

Applying the theorem of Fejér and Riesz to $f(z)=z /(1-z)^{\alpha}$ we have

$$
\begin{aligned}
L(r) & =\int_{0}^{2 \pi}\left|z f^{\prime}(z)\right| d \theta=\int_{0}^{2 \pi}|z|\left|\frac{1-z+\alpha z}{(1-z)^{\alpha+1}}\right| d \theta \\
& \geqq 2 r \int_{-r}^{r} \frac{1-\rho+\alpha \rho}{(1-\rho)^{\alpha+1}} d \rho \\
& =O(1-r)^{-\alpha} \quad \text { as } r \rightarrow 1 .
\end{aligned}
$$

This completes our proof.

The author would like to acknowledge helpful comments made by the referee. 


\section{REFERENCES}

1. I. E. Bazilevič, On a case of integrability in quadratures of the Loewner-Kufarev equation, Mat. Sb. 37 (79) (1955), 471-476. (Russian) MR 17, 356.

2. Ch. Pommerenke, On starlike and convex functions, J. London Math. Soc. 37 (1962), 209-224. MR 25 \#1279.

3. - On starlike and close-to-convex functions, Proc. London Math. Soc. (3) 13 (1963), 290-304. MR $26 \# 2597$.

4. Z. Nehari, Conformal mapping, McGraw-Hill, New York, 1952. MR 13, 640.

5. M. Nunokawa, On Bazilevič and convex functions, Trans. Amer. Math. Soc. 143 (1969), 337-341.

6. D. K. Thomas, On starlike and close-to-convex univalent functions, J. London Math. Soc. 42 (1967), 427-435. MR $35 \# 6812$.

7. —_ On Bazilevic functions, Trans. Amer. Math. Soc. 132 (1968), 353-361. MR $36 \# 5330$.

8. - A note on starlike functions, J. London Math. Soc. 43 (1968), 703-706. MR $37 \# 4248$.

Gunma University, JaPAN 